\title{
Features and Inspirations of Performance Framework for Regional Universities in Australia
}

\author{
https://doi.org/10.3991/ijet.v15i18.16743 \\ Fei Gao \\ Zhejiang Shuren University, Hangzhou, China \\ gaofeibde163. com
}

\begin{abstract}
Regional universities are common around the world, and important to the higher education system. This paper mainly analyzes the features of performance framework for regional universities in Australia, and discusses how the framework inspires the performance evaluation of regional universities in China. Firstly, the main features of Australian regional universities were summarized as the diversity of students, the strong local features, and the important social influence. Then, the key components of the performance framework, namely, core, optional, and institution-specific measures, were introduced in great details. Drawing on the framework and the local conditions, several suggestions were put forward to promote the performance evaluation of regional universities in China: develop high-level universities, serve local development, and diversify evaluation standards. The research results help to promote higher education in China and beyond.
\end{abstract}

Keywords-Regional universities, performance framework, Australia, evaluation.

\section{Introduction}

In China, universities are either funded by the ministries/commissions of the state council or affiliated to local governments. According to 2019 statistical bulletin on China's national educational development, only 100 out of the 1,265 universities in the country are directly under the ministries/commissions [1], while over $90 \%$ of them are run by local governments. The latter are generally known as regional universities, for they are administered by departments at provincial level or below.

The numerous regional universities can be divided into three categories: the Double First-Class (DFC) universities, provincial key universities, and ordinary universities. The DFC is an initiative to create world-class universities and disciplines by the end of 2050. Currently, regional universities take up 50\% of 12 Class B universities that have the potential to grow into world-class universities, and open $46.3 \%$ of all 95 disciplines that lead the way to world-class excellence. The few regional universities covered in the DFC Initiative are very competitive, influential, and reputable across China. 
The provincial key universities enjoy immense popularity and offer the best education in the region, thanks to the support from the provincial government. Most of these universities boast a long history and run various disciplines. Some of them have the right to confer master's degree or doctor's degree.

The common universities account for more than half of all regional universities. They are generally promoted, transformed, or merged from secondary vocational schools or higher vocational universities. The common universities are mainly administrated by municipal governments and funded by local and social channels. Apart from academics, these universities focus on the application of knowledge to practice. Only a few of them have the right to confer master's degree. In terms of location, the majority of these universities lies in underdeveloped areas.

The regional universities in China are highly similar to their counterparts in Australia, especially the newly established undergraduate universities. In Australia, regional universities usually reside outside metropolitan areas, and maintain a close relation with the local government. Although far away from population, cultural or economic centers, the locations of these universities are important to national development. To enhance cooperation, six regional universities have formed a Regional Universities Network (RUN).

In the light of the above, this paper firstly analyzes the main features of Australian regional universities, and then introduces the performance framework for these universities. Next, the evaluation based on the performance framework was expounded. On this basis, three important strategies were presented to improve the performance evaluation of regional universities in China.

\section{Main Features of Australian Regional Universities}

According to Australian Bureau of Statistics, the population of Australia stands at 24.6 million in 2017. As shown in Figure 1, 71.83\% of the total population live in major cities, and the rest live in other areas. The vast majority of Aboriginal and Torres Strait Islander people dwells in the latter areas [2].

Statistics in 2016 show that 13 universities are headquartered outside major cities, and nearly 30 universities have at least one campus in remote areas [3]. Besides traditional functions like teaching and research, regional universities play an important role in regional economy, social development, and cultural life. More importantly, these universities can effectively prevent brain drain, create lots of jobs, and promote regional investment in research and development $(R \& D)$. 


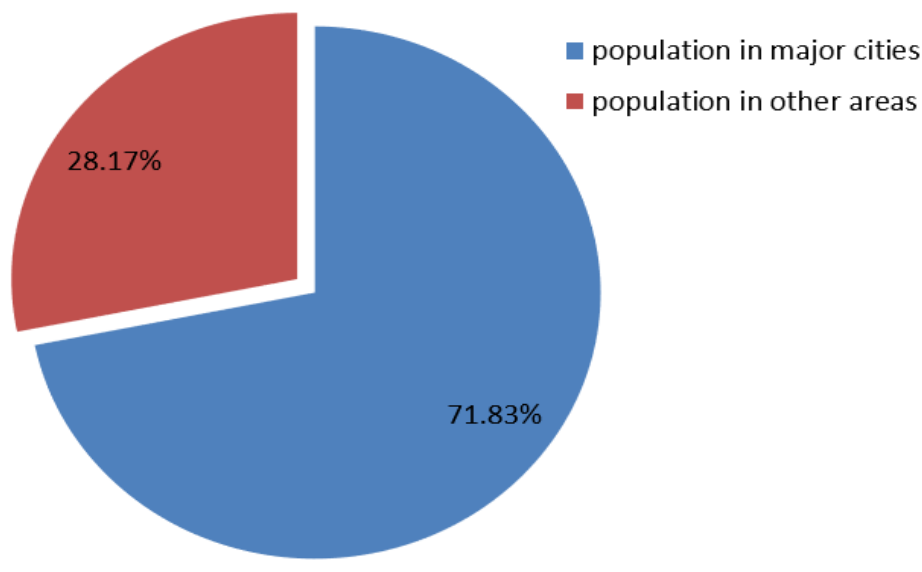

Fig. 1. Spatial distribution of population in Australia

\subsection{Diversity of students}

Unlike those in metropolitan universities, many students in regional universities have regional, remote or indigenous backgrounds, or have a reported disability [4], that is, the students in regional universities are highly diverse.

In regional universities, many students choose to work part time and study off campus. Besides academic pressure, these students also face professional pressure and family burden. Compared with those in metropolitan universities, regional university students need to spend lots of time to complete their studies, and face a high probability to drop out of school, according to the non-completion risks of different groups of university students (Figure 2) [5].

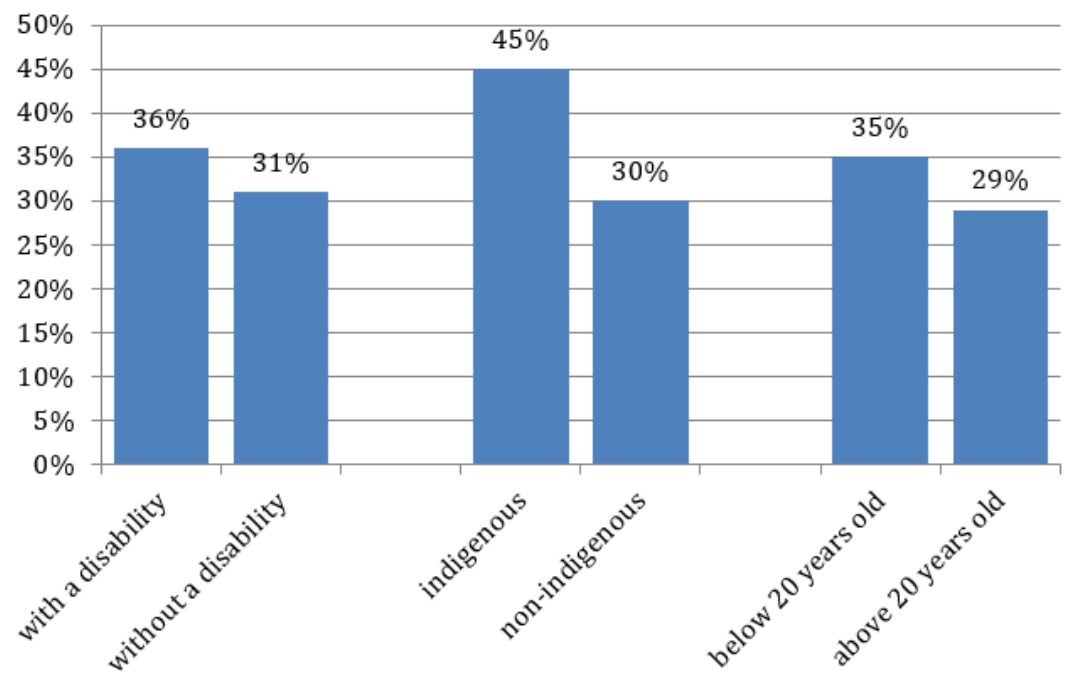

Fig. 2. Proportion of university students with non-completion risks in different groups 
The diversity of students demonstrates the efforts of regional universities in meeting the educational needs of the disadvantaged. Despite these efforts, the population of the right age in major cities in Australia enjoy more educational opportunities than that in regional and remote areas (Figure 3) [3]. Regional universities must further expand their scale and recruit more students from non-metropolitan areas.

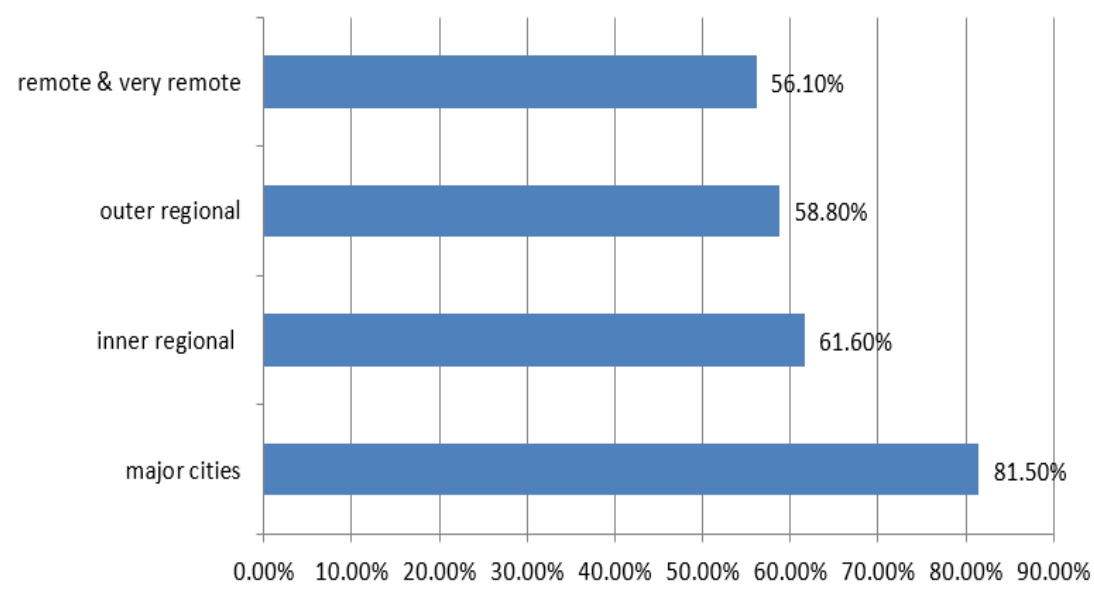

Fig. 3. Proportion of those aged 25-34 with Year 12 or above (2014)

\subsection{Strong local features}

Regional universities in Australia have been actively participating in regional development, making great contributions to regional governance, community service and economic growth. These universities have strong local features in terms of talent cultivation, scientific research, and social service.

On talent cultivation, regional universities provide local students with high-level professional education with local characteristics. Lots of local students are attracted to these universities, which are close to home, low in cost, and integrated into their social circle. After graduation, most students live and work locally, alleviating the brain drain in these non-metropolitan areas.

On scientific research, regional universities run many scientific research programs that are closely related to regional society, ranging from community construction, regional economic growth, and local governance. Through these programs, the techniques of multiple disciplines are put into practice, in the light of regional characteristics.

On social service, regional universities are important participants in various regional activities, by virtue of their experience, personnel and facilities. For example, The University of the Sunshine Coast (USC) Psychological Clinic, in association with Asperger Services Australia Ltd., established an Asperger's Support Group to provide families of autistic children with consultation, lecturing, and personnel training. Central Queensland University worked with state and local governments and enterprises to monitor the channels of the local Fitzroy River Basin [6]. 


\subsection{Important social influence}

Australian regional universities have brought important economic, political and cultural added values to the local areas and beyond and served as the key pillars of local development.

In the field of economy, graduates from regional universities meet the demand for laborers with good skills and rich experience. From 2013-2016, 69\% bachelors and $55 \%$ of masters from RUN universities ended up working in regional areas [7]. The universities and their members are important consumers. The students in RUN universities alone spend 4.8 million AUD each year, while these universities spend a total of 1.59 billion AUD each year [8]. In addition, the R\&D activities of these universities are major driving engines of economic growth. By the Computable General Equilibrium (CGE) model, the R\&D activities in the RUN worth 179 million AUD in 2015 [9].

In the political field, regional universities help to ensure regional stability by enhancing the governance ability at the grass roots, strengthening the sense of belonging and cohesion of local social members, and breaking the intergenerational cycle of disadvantage.

In the field of culture, regional universities provide the personnel, venues, facilities, and projects needed to carry out local activities and enrich the community life. More importantly, many regional universities have opened special institutions to protect the historical documents of the region.

\section{Performance Framework for Australian Regional Universities}

In recent years, Australian universities have expanded their enrollment, raising concerns about the education quality after the expansion. Amidst the concerns, the RUN attempted to develop a performance framework that reflects the uniqueness of regional universities and clarifies the focus of future development for these universities. In April 2018, the RUN entrusted Nous Group, the largest management consulting company in Australia, to develop framework to measure the performance of its members from internal and external perspectives. 
Table 1. The performance framework for Australian regional universities

\begin{tabular}{|c|c|c|}
\hline Category & Core measures & Optional measures \\
\hline Teaching quality & $\begin{array}{l}\text { 1.Completion } \\
\text { 2.Attrition } \\
\text { 3.Student satisfaction }\end{array}$ & \multirow{3}{*}{$\begin{array}{l}\text { Each institution to select optional } \\
\text { measures from a pre-approved list }\end{array}$} \\
\hline Equity & $\begin{array}{l}\text { 4.Participation rates for equity } \\
\text { groups }\end{array}$ & \\
\hline $\begin{array}{l}\text { Meeting Social, cultural \& } \\
\text { economic need }\end{array}$ & $\begin{array}{l}\text { 5.Employer satisfaction } \\
\text { 6.Employment outcomes }\end{array}$ & \\
\hline Category & Core measures & $\begin{array}{l}\text { Institution-specific measure (up to } \\
\text { one) }\end{array}$ \\
\hline Teaching quality & $\begin{array}{l}\text { 1.Completion } \\
\text { 2.Attrition } \\
\text { 3.Student satisfaction }\end{array}$ & \multirow{3}{*}{$\begin{array}{l}\text { Each institution may negotiate an } \\
\text { additional metric }\end{array}$} \\
\hline Equity & $\begin{array}{l}\text { 4.Participation rates for equity } \\
\text { groups }\end{array}$ & \\
\hline $\begin{array}{l}\text { Meeting Social, cultural \& } \\
\text { economic need }\end{array}$ & $\begin{array}{l}\text { 5.Employer satisfaction } \\
\text { 6.Employment outcomes }\end{array}$ & \\
\hline
\end{tabular}

As shown in Table 1, the performance framework [10] consists of multiple measures in three dimensions: teaching quality, equity, and meeting social, cultural \& economic need. Together, these measures fully reveal the basic situation and typical features of regional universities.

\subsection{Integration between general requirements and local features}

The Higher Education Support Act 2003 (HESA), the main piece of legislation governing higher education in Australia, calls for a higher education system characterized by quality, diversity, and equity of access [11]. Based on these general requirements, teaching quality, equity and meeting social, cultural \& economic need were selected as the three dimensions of the performance framework for regional universities.

Besides the general requirements, the performance framework highlights the local features of regional universities: improving teaching quality, absorbing disadvantaged groups, and serving regional society. Teaching quality is the core issue of regional universities, whether they focus on higher education or vocational education. Disadvantaged groups are a valuable asset to regional universities, rather than a burden. Social service is also important to regional universities, because Australian higher education is a demand-driven system.

\subsection{Integration between core, optional, and institution-specific measures}

Regional universities have many common features in mission, goals, and operation mechanism. Meanwhile, each regional university has unique features arising from location, tradition, culture, and strength. The performance measures of regional universities were selected based on the experience of many countries, especially the US. For example, there are five core measures and five optional measures in the Concep- 
tual Framework for Pennsylvania State System of Higher Education 2012-2017 Performance Funding Program [12].

The performance framework for Australian regional universities fully integrates core, optional, and institution-specific measures. A total of six core measures were designed, such as employer satisfaction, student satisfaction, participation rates of equity groups, weighted attrition, completion rates, and employment outcomes.

The optional measures give regional universities some flexibility. In the dimension of teaching quality, the optional measures include teaching incentives, \% students engaged in work placements, graduate starting salary, progression to further qualifications, etc. In the dimension of equity of access, the optional measures include resources for student support, closing the achievement gap, closing the gap in professional accreditation, etc. In the dimension of meeting social, cultural \& economic need, the optional measures include $\%$ graduates in areas of national/regional priority, $\%$ of budget spent on activities with direct community benefit, economic value of the university to the local community, etc. [10]

In addition, each regional university can negotiate with the government to set up an institution-specific measure, which could be the success of dual sector arrangements or support for regional disaster relief.

\subsection{Integration between outputs, outcomes, and impact}

The performance framework considers the outputs, outcomes, and impact of regional universities, providing a full picture of its overall competitiveness.

Outputs, as the most intuitive results of a university, are often presented in the form of quantitative data. The outputs in the performance framework cover core measures like attribution, completion, and participation rates for equity groups, as well as optional measures like $\%$ graduates in areas of national/regional priority. Among them, attribution and completion should be weighted as per the actual situation. Suppose a university has a six-year completion rate of $60 \%$, below the national average of $70 \%$. However, the university also has significantly higher proportions of students with high non-completion risk, including part time ( $43 \%$ vs. $29 \%$ ), off campus ( $48 \%$ vs. $15 \%$ ), low-SES ( $28 \%$ vs. $16 \%$ ), indigenous ( $4 \%$ vs. $2 \%$ ), and disability ( $7 \%$ vs. $5 \%$ ). By the weighting formula, the university will have a completion rate of $74 \%$ if it has average numbers of these student cohorts [10].

Focusing on the effects on individuals, organizations and society, outcomes are more subjective than outputs. The main outcomes of regional universities are student satisfaction rates, employer satisfaction, and employment outcomes. Among them, student satisfaction rates measure the overall student experience, teaching quality, student support, and learning environment

The impacts highlight the long-lasting effects of regional universities in a wide scope. For a regional university, its impacts can be evaluated against optional and institution-specific measures. For example, graduate starting salary, and progression to further qualifications reflect on the impact of the university on the life quality of students in the future; closing the achievement gap demonstrates how much the university benefits the community and residents. 


\section{Performance Framework-Based Evaluation}

The evaluation based on the performance framework involves a series of processes, namely, setting up an evaluation team, submitting performance reports, and giving an integrated score. Considering the purpose of higher education in Australia, various stakeholders are invited to make reasonable judgements, and the opinions of regional universities are also taken into account. The entire evaluation process is transparent, standardized, and orderly. The main features of the evaluation process are introduced below.

\subsection{Independence}

The independence of the evaluation process guarantees the fairness of the results. The evaluation team includes various stakeholders (e.g. experts, students, and university managers), excluding government officials. With diverse experience, the stakeholders work together to evaluate the performance of the target university from multiple angles. The experts judge the level of the university based on disciplines and specialties. The students assess the importance and value of experience and services provided by the university. The managers appraise the overall performance of university functions. In this way, the development trend and features of the target university can be investigated systematically, promoting the fair competition between universities.

\subsection{Standardization}

To facilitate data analysis and comparison, the RUN requires all its members to submit performance reports in a unified format:

1) The report should not surpass 15 pages in length

2) The contents should meet the relevant standards, and reflect the objectives of the HESA

3) The report should contain four parts, namely, strategic context, teaching quality, equity of access, and social, cultural \& economic need

4) Each part of the report should provide the basic information and clarify the existing problems [10]

The format unification not only saves the preparation cost of the performance report, but also enables the evaluation team to assess the performance in a proper, accurate, and comprehensive manner.

\subsection{Interactivity}

The performance evaluation is an interactive process. Drawing on the Teaching Excellence Framework (TEF) in UK, regional universities attach great importance to the original data and background factors (e.g. student age, and professional features) in the performance report [13]. To protect their rights and interests, regional universi- 
ties should elaborate their features, introduce their backgrounds, and explain their deficiencies.

The evaluation team should be provided with three types of information: the quantitative data about the national and international impacts of the university; the university development background, including the justification for the poor performance in some fields; the cases and stories about the mission, value and impact of the university.

Take the calculation of attrition rate for example. Some students might return to the university and resume their programs in the near future. This possibility must be considered before computing the attrition rate. Besides, the main reasons of attribution should be analyzed to exclude the cases not caused by the university. After all, some students may drop out of school due to family conditions, and the previous education.

During the evaluation, the evaluation team should allow the target university to explain its deficiencies, and consider the impacts of special events, such as local economic shocks or regional natural disasters, on university performance.

\section{$5 \quad$ Inspirations on Regional Universities in China}

Regional universities directly bear on the scale and quality of higher education in a country. Similar to their counterparts in Australia, regional universities in China will play an increasingly important role in meeting local social needs, promoting regional innovation, and forging high-quality brands.

\subsection{General purpose of regional universities}

Despite the inferiority of location and student sources, quite a few regional universities in Australia have managed to gain international reputation for high-quality education and contributed greatly to local development. From 2006 to 2013, the RUN universities witnessed a 97\% growth in grant income and a $126 \%$ growth in industrial income, both of which are higher than the overall growths (76\% and 48\%) in higher education over the same period [14].

To promote higher education, regional universities in China must strive to become high-level universities based on their positionings. The construction of high-level universities demands the top-level design of the local government, and though innovation of regional universities.

The local government should fully integrate resources, step up coordination, and improve governance, creating the path towards healthy and sustainable higher education. Many regions have put forward plans to develop high-level regional universities, such as the innovation center construction plan of Beijing, the 1331 project of Shanxi, and the high-level university plan of Guangdong. Meanwhile, the local government should provide policy support and resource guarantee to the construction of high-level universities. For instance, the regional universities should be given the autonomy to select, appoint, and promote teachers. 
The regional universities should reform the thinking pattern, develop new areas of strength, and divert resources to these areas, aiming to overtake their competitors. Many regional universities have already implemented innovative programs: those focusing on applied technology have given full play to the close relations with enterprises; those focusing on teaching and service have reshaped their teaching plan to meet the needs of service objects.

\subsection{Core competitiveness of regional universities}

For various reasons, every regional university must maintain a good relationship with the region, and actively participate in the local social development: the local government is usually the largest funder of the university; most students come from the local region; the education scale and quality depend on the regional development. Inspired by the performance framework for Australian regional universities, the regional universities in China should enhance their core competitiveness from the following aspects:

Firstly, regional universities, especially newly established ones, should pay special attention to the quality of undergraduate education, and arrange suitable curriculum and faculty members for this purpose. Many Australian regional universities have set good examples: The University of New England included community engagement as part of the learning contents; Federation University Australia encouraged student leaders to help less experienced peers; James Cook University launched a mentor program to support freshmen [15].

Secondly, regional universities should further popularize higher education. In fact, the proliferation of higher education is an irreplaceable task of all universities. Mimicking their Australian counterparts, regional universities in China should actively absorb students from rural areas and poor families and provide education chances to adults. This measure will alleviate the imbalance of education resources in the region.

Thirdly, regional universities should align their functions with the demand of local socioeconomic development, and the national and global situations. For example, the high-tech achievements should be put into practice, and the knowledge innovations should be introduced to promote local development.

\subsection{Key support to regional universities}

Higher education, as a public product, must be supervised by all parties. The diversity of evaluation subjects is not negligible in the evaluation based on the performance framework. Otherwise, the evaluation will be incomplete and inaccurate. Moreover, the uniqueness of each regional university should also be considered in the evaluation.

Due to the sheer number of regional universities in China, it is impossible to evaluate the performance of every regional university strictly by the same standard. Different evaluation metrics should be adopted for different regional universities, such as to recognize their respective peculiarities and strengths.

Specially, the local government should continue to support the regional universities that have the potential to grow into world-class universities or develop world-class 
disciplines, enabling them to enhance the current advantages and seek new breakthroughs. The newly built regional universities should not be ignored by the local government. Anhui Province has planned to develop three kinds of DFC universities, characteristic high-level universities, and skilled high-level universities. Jiangxi Province divided regional universities into those with comprehensive strength and those with industrial strength and offered both sustained support [16].

Finally, the evaluation should take account of diverse factors, namely, current situation, student level, and faculty quality, so as to promote the overall strength of higher education in the region.

\section{Conclusions}

1. There are three main features of regional universities in Australia: the students are of diverse backgrounds, while the universities have strong local features and important social influence.

2. The performance framework for Australian regional universities fully integrates general requirements with local features, deeply fuses core, optional, and institution-specific measures, and effectively blends outputs, outcomes, with impact.

3. Based on the performance framework, the performance evaluation of Australian regional universities ensures fairness through independence, facilitates comparison through standardization, and realizes comprehensiveness through interactivity.

4. Drawing on the performance framework and the local conditions, China should improve the performance of regional universities by persisting in high-level direction, serving local development, and diversifying evaluation standards.

\section{$7 \quad$ Acknowledgement}

This paper is supported by 2020 Planning Program of Philosophy and Social Sciences in Zhejiang Province" Research on the Evaluation Model and Promotion Path of Industry- University Integration Performance from the Perspective of Resource Integration -- Taking Zhejiang Province as an Example" (No. 20NDJC166YB).

\section{References}

[1] Ministry of Education of the People's Republic of China. (2020). National Statistical Bulletin of Education Development in 2019. http://www.moe.gov.cn ljyb sjzl/sjzl fztjgb/202005/t20200520 456751.html

[2] Australian Bureau of Statistics. (2018). Regional Population Growth, Australia. https://www.abs.gov.au/Population.2018.04.28

[3] Devlin, M., McKay, J. (2017). Facilitating success for students from low socioeconomic status backgrounds at regional universities. Victoria: Federation University.

[4] Nelson, K., Picton, C., McMillan, J., Edwards, D., Devlin, M., Martin, K. (2017). Understanding the completion patterns of equity students in regional universities. Perth, 
WA: National Centre for Student Equity in Higher Education (NCSEHE), Curtin University.

[5] Cherastidtham, I., Norton, A., Mackey, W. (2018). University attrition: What helps and what hinders university completion. Grattan Institute.

[6] Regional Universities Network. (2013). Regional Universities Network: engaging with regions, building a stronger nation. Canberra, ACT, Australia.

[7] Regional Universities Network. (2018). Jobs and productivity effects of the regional universities network. Canberra, ACT, Australia.

[8] Regional Universities Network. (2018). RUN briefing pack. http://www.run.edu.au/resources/RUN\%20briefing\%20pack\%20June\%202018.pdf

[9] Regional Universities Network. (2018). The economic impact of the Regional Universities Network. http://www.run.edu.au/resources/RUN\%20Economic\%20impact\%20report\%20final.pdf

[10] Nous Group \& Regional Universities Network. (2018). A Performance Framework for Regional Universities. Canberra: Nous Group.

[11] Australian Government Department of Education and Training. (2003). Higher Education Support Act 2003 (HESA). https://www.legislation.gov.au/Series/C2004A01234

[12] Pennsylvania State System of Higher Education. (2013). 2012-2017 Performance Funding Program.

[13] Baker, S. (2017). TEF: In-depth analysis of the results. https://www.timeshighereducation.com/features/tef-in-depth-analysis-of-results

[14] Regional Universities Network. (2015). RUN Research: Regionally Embedded, Globally Engaged. Canberra: Regional Universities Network.

[15] Nelson, K., Readman, K., Stoodley, I.D. (2016). Shaping the 21st century student experience at regional universities: Final Report. Australian Department of Education and Training: Canberra.

[16] Zhang, W., Zhang, M.C. (2018). Comparison of inter-provincial policies of "Double FirstClass" in China: Based on textual analysis of 26 provinces' "Double First-Class" guidelines Journal of Higher Education Management, 12(4): 19-26.

\section{$9 \quad$ Author}

Fei Gao, as the associate researcher of Non-governmental Higher Education Institute of China, Zhejiang Shuren University, has been committed to the research in the field of higher education evaluation for a long time. She has published several core papers and finished several important projects.

Article submitted 2020-06-09. Resubmitted 2020-07-05. Final acceptance 2020-07-06. Final version published as submitted by the authors. 